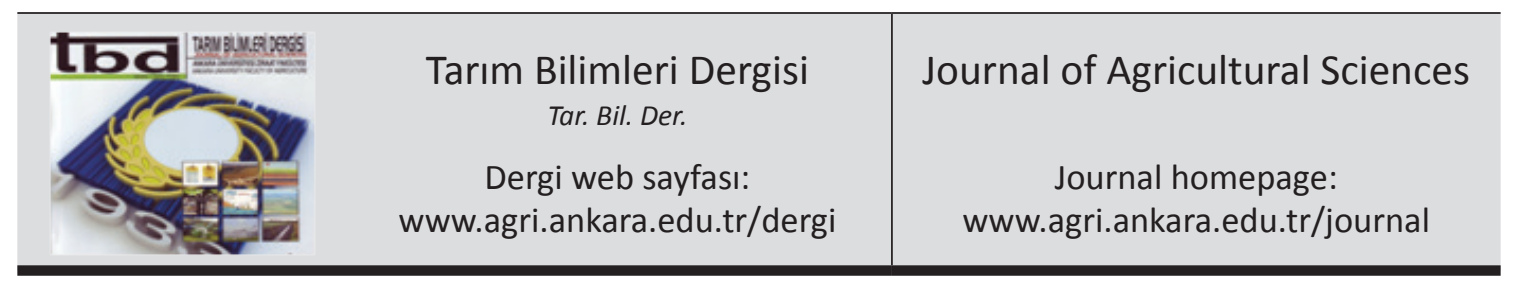

\title{
Güneş Destekli Isı Pompalı Bir Kurutucuda Mantarın Kuruma Davranışlarının Yapay Sinir A ğı Kullanılarak Modellenmesi
}

\author{
Seyfi ŞEVIKK ${ }^{\mathrm{a}}$, Mustafa AKTAŞ ${ }^{\mathrm{b}}$, M. Bahadır ÖZDEMİR ${ }^{\mathrm{b}}$, Hikmet DOĞAN \\ ä́̈̈n̈̈ Mahallesi, Batıkent, 06370, Ankara, TÜRKIYE \\ ${ }^{\boldsymbol{b}}$ Gazi Üniversitesi, Teknoloji Fakültesi, Enerji Sistemleri Mühendisliği Bölümü, Teknikokullar, Beşevler, 06500, Ankara, TÜRKIYE
}

\section{ESER BİLGISİ}

Araștırma Makalesi DOI: 10.1501/Tarimbil 0000001278

Sorumlu Yazar: Seyfi Şevik, E-posta: seyfisvk@hotmail.com, Tel: +90 (312) 2028707

Geliş Tarihi: 16 Eylül 2013, Düzeltmelerin Gelişi: 22 Kasım 2013, Kabul: 24 Kasım 2013

\begin{abstract}
ÖZET
Kurutucu, güneş enerjili ve güneş enerjisi destekli 1sı pompalı olmak üzere ayrı ayrı $45{ }^{\circ} \mathrm{C}$ ve $55{ }^{\circ} \mathrm{C}$ kurutma havası sıcaklığ $0.9 \mathrm{~m} \mathrm{~s}^{-1}$ ve $1.2 \mathrm{~m} \mathrm{~s}^{-1}$ hava hızlarında mantar kurutularak test edilmiştir. Deneylerden elde edilen nem içeriği (MC), ayrılabilir nem oranı (MR) ve kurutma hızı (DR) değerleri Levenberg-Marquardt (LM) geri yayılım öğrenme algoritması ve Fermi transfer fonksiyonu kullanılarak yapay sinir ağları (YSA) ile modellenmiştir. Geliştirilen modelin istatistiksel geçerliliğinin belirlenmesinde kullanılan çoklu belirleme katsayısı $\left(\mathrm{R}^{2}\right)$, ortalama hata kareleri karekökü (RMSE), ve ortalama mutlak hata yüzdesi (MAPE) istatistik değerleri kullanılmıştır. R ${ }^{2}$, RMSE ve MAPE sırasıyla MC için 0.998, 0.0015608, 0.1940471, MR için 0.998, 0.0000971, 0.2214687 ve DR için 0.993, 0.0000075, 0.8627478 olarak elde edilmiştir. Böylece, farklı kurutma şartları için bu modelleme ile mantarın kuruma davranışları başarılı bir şekilde analiz edilebilir.
\end{abstract}

Anahtar Kelimeler: Güneş destekli 1sı pompası; Kurutma; Yapay sinir ağları; Mantar

\section{Modeling of Drying Behaviors of Mushroom in a Solar Assisted Heat Pump Dryer by Using Artificial Neural Network}

\section{ARTICLE INFO}

Research Article

Corresponding Author: Seyfi Şevik, E-mail: seyfisvk@hotmail.com, Tel: +90 (312) 2028707

Received: 16 September 2013, Received in Revised Form: 22 November 2013, Accepted: 24 November 2013

\begin{abstract}
Dryer was tested by drying mushroom with solar energy and solar assisted heat pump separately at $45^{\circ} \mathrm{C}$ and $55^{\circ} \mathrm{C}$ drying air temperature and $0.9 \mathrm{~m} \mathrm{~s}^{-1}$ and $1.2 \mathrm{~m} \mathrm{~s}^{-1}$ drying air velocities. Moisture content (MC), moisture ratio (MR) and drying rate (DR) which were obtained from experiments were modeled by using Levenberg-Marquardt (LM) the backpropagation learning algorithm and fermi transfer function with artificial neural networks (ANNs). The coefficient of multiple determination $\left(\mathrm{R}^{2}\right)$, the root means square error (RMSE) and the mean absolute percentage error (MAPE) were used for the determination of statistical validity of the developed model. $\mathrm{R}^{2}$, RMSE and MAPE were determined for MC
\end{abstract}


0.998, 0.0015608, 0.1940471, MR 0.998, 0.0000971, 0.2214687 and DR 0.993, 0.0000075, 0.8627478 respectively. In this way, drying behaviors of mushroom can be analyzed successfully for different drying conditions with this modeling. Keywords: Solar assisted heat pump; Drying; Artificial neural networks; Mushroom

(C) Ankara Üniversitesi Ziraat Fakültesi

\section{Giriş}

Mantar, daha çok taze olarak tüketilen bir sebze türü olmasına karşın son yıllarda kuru olarak tüketimi artan bir üründür. Dünyada en çok üretimi yapılan halk arasında kültür mantarı olarak bilinen "Agaricus bisporus" türüdür. Genel olarak mantarların \% 90'a yakını sudur, sadece \% 10 kadarı kuru kütledir. $\mathrm{Bu}$ kuru kütlenin içeriğini ise karbonhidratlar, proteinler, yağlar, vitaminler ve madensel tuzlar oluşturmaktadır. Dünyada üretilen yemeklik mantarların \% 40-50'si taze olarak tüketilirken geri kalanı konserve, dondurulmuş veya kurutulmuş olarak pazarlanmaktadır. Endüstriyel olarak işlenmiş mantarların en büyük grubu konserveler, ikinci grubu geçici olarak muhafaza edilen mantarlar, üçüncü grubu toptan ve perakende satış için dondurulan mantarlar, ticaretin küçük bir parçasını ise sirke veya diğer asitlerle korunmuş mantarlar ve kuru mantarlar oluşturmaktadır. Mantar kurutulduğunda tadını ve diğer özelliklerini hemen hemen aynen korur. Kurutulmuş mantar kuru haliyle kullanılabildiği gibi, ögütülerek mantar unu olarak da kullanılabilmektedir (Şevik 2011). Kurutulmuş mantarın besin ve vitamin içeriği değerleri Çizelge 1'de verilmiştir.

Türkiye'de mantarlar, Kasım 2005 TS 2410 sayılı "Kültür mantarları-taze" Türk Standardı ile denetlenmektedir. Türkiye'de katma değeri yüksek olan işlenmiş mantar ihracatı 2008 yılına kadar yok denecek kadar az iken (\% 1'in altında) 2008 yılında \% 7'ye yükselmiştir. 2008-2009 yıllarında mantar, Türkiye'nin yaş sebze ihracatında ilk 5 ürün içerisinde yer alan ve ihracatından elde edilen gelirin yüksek olduğu bir üründür (EYMSİB 2010). Aynı şekilde kurutulmuş halinin de geliri yüksektir. Çizelge 2'de yıllara göre kurutulmuş mantar ihracat miktarları ve gelirleri verilmektedir.

Tarımsal ürünler hasat edildikten sonra da solunum faaliyetlerine devam ettikleri için bozulma olayı da hızlı bir şekilde gerçekleşir (Alibaş 2012). Mantar da çok çabuk bozulan bir ürün olduğundan tüketim süresi gibi kurutma süresinin de kısa olması gerekir. Teknik metotlar ile yapılan kurutma esnasında

Çizelge 1- Kurutulmuş mantarın besin ve vitamin içeriği (mg $100 \mathrm{~g}^{-1}$ kuru madde $\left.^{-1}\right)$ değerleri (Boztok ve Erkip 2002)

Table 1- Nutriment and vitamin content of dried mushroom (mg $100 \mathrm{~g}^{-1}$ dry matter $^{1}$ )

\begin{tabular}{lccccccccc}
\hline $\begin{array}{l}\text { Mantar } \\
\text { Türü }\end{array}$ & $\begin{array}{c}\text { Protein } \\
(\%)\end{array}$ & $\begin{array}{c}\text { Karbonhidrat değerleri } \\
(\%)\end{array}$ & $\begin{array}{c}\text { Yăg } \\
(\%)\end{array}$ & $\begin{array}{c}\text { Lif } \\
(\%)\end{array}$ & $\begin{array}{c}\text { Enerji } \\
(\text { kcal })\end{array}$ & Thiamine & Niacine & Riboflavin & Askorbik asit \\
\hline $\begin{array}{l}\text { Agaricus } \\
\text { bisporus }\end{array}$ & $23.9-34.8$ & $51.3-62.5$ & $1.7-8.3$ & $8-10.4$ & $328-381$ & 1.1 & 55.7 & 5 & 81.9 \\
\hline
\end{tabular}

Çizelge 2- Yıllara göre kurutulmuş mantar ihracat değerleri (DPT 2001; Kahyaoğlu 2008)

Table 2- Dried mushroom export values according to years (DPT 2001; Kahyaoğlu 2008)

\begin{tabular}{lllllllllllll}
\hline & Yllar & 1994 & 1995 & 1996 & 1997 & 1998 & 1999 & 2000 & 2004 & 2005 & 2006 & 2007 \\
\hline \multirow{2}{*}{ İhracat } & Ton & 38.6 & 64.4 & 233.9 & 36.7 & 68 & 21 & 35 & 19 & 27 & 34 & 21 \\
& $x 1000 \$$ & 2810 & 5289 & 3252 & 1713 & 1972 & 2490 & 999 & 1071 & 1243 & 2389 & 1710 \\
\hline
\end{tabular}


yüksek miktarda enerjiye ihtiyaç duyulmaktadır. Kurutulacak üründen buharlaştırılan birim miktardaki nem için harcanan enerji miktarı kurutma sistemlerinde enerji ekonomisi için önemlidir (Ceylan \& Aktaş 2008a). Bununla birlikte kurutma işlemi; ürün, ürün tipi, ürünün kalınlığı, ürünün nem içeriği, hava sıcaklığı, hava hızı ve hareketi, nem difüzyon, kurutma yöntemi ve firın yapısı gibi pek çok iç ve dış faktörlerden etkilenmektedir (Şevik et al 2013). Dünyada ticareti yapılan kurutulmuş sebzelerin \% 97-98'i kontrollü şartlarda sıcak hava ile kurutulmaktadır. Türkiye, kurutulmuş sebze konusunda ihracatçı ülke konumundadır. Toplam kurutulmuş ürün ihracatının \% 92'sini kurutulmuş domates oluşturmaktadır. Domatesten sonra ise patlıcan ve mantar sayılabilir (Şevik 2011).

Güneş enerjisi ve 1sı pompası sistemlerinin tekil kullanılmak yerine her iki sistemin avantajlarından yararlanabilmek için birlikte kullanılmasıyla sistem performans değeri arttırılmaktadır. Bu tür sistemler, güneş kolektöründe 1sitılan suyun veya havanın is1 pompasının 1S1 kaynağı olarak kullanıldığı güneş destekli 1sı pompası (GDIP) ve güneş kolektörünün 1S1 pompasının buharlaştırıcısı olarak kullanıldığı direkt genleşmeli güneş destekli 1Sı pompası (DGGDIP) olmak üzere iki şekilde kullanılmaktadır. Bu konuda ilk çalışma 1955 yılında Batı Virginia'da Sporn \& Ambrose (1955) tarafindan ortaya konmuştur. İlk başlarda su 1sıtma amaçlı yapılan bu sistemler, sonraları kurutma amaçlı olarak da kullanıla gelmiştir. Best et al (1996), pirinç kurutma için GDIP kurutucusu performansını araştırmış ve performans katsayısı (COP) değerini 5.3 olarak bulmuşlardır. Hawlader \& Jahangeer (2006), GDIP kurutucusunun ve su 1sıtıcısının performansını araştırmışlardır. $\mathrm{Bu}$ amaçla bir benzetim programı geliştirilmiştir. Ceylan \& Aktaş (2008b), 1sı pompalı endüstriyel fındık kurutma firınında kurutma şartları göz önünde bulundurularak 40,45 ve $50^{\circ} \mathrm{C}$ sicaklıklarda fındık kurutmuşlar ve enerji analizi yapmışlardır. Çalışmalarında enerjinin kullanılma oranı \% 43-65 olarak bulunmuştur. Li et al (2010) tarafindan bir tahıl ambarı için güneş destekli ısı pompası kurutma sistemi tasarlanmıştır. Ünitenin güneş enerjisinden yararlanma oranı $\% 20$ 'den daha yüksek, COP değeri
5.19 ve SMER değeri $3.05 \mathrm{~kg} / \mathrm{kWh}$ olarak elde edilmiştir. Şevik (2011), sulu güneş kolektörü ve 1s1 pompasının ayrı ayrı veya birlikte kullanılabildiği, 1sıtma ve kurutma için sicak hava üreten bir sistem tasarımı yaparak bir mekanın 1sıtılmasını ve mantar kurutulmasını deneysel olarak incelemiştir. Şevik (2013), $50{ }^{\circ} \mathrm{C}$ sicaklıkta ve kurutma esnasinda 0.4$0.9 \mathrm{~m} \mathrm{~s}^{-1}$ aralığında değişen hava hızlarında havuç kurutarak çift geçişli havalı kolektörlü 1sı pompalı bir kurutucunun kolektör performansını analiz etmiştir.

Mantar kurutma ile ilgili son zamanlarda bir çok çalışma yapılmıştır. Nehru et al (1995), günlük $2.5 \mathrm{~kg}$ kurutma kapasiteli bir güneşli kurutucuda "Pleurotus Florida" tipi mantar kurutmuşlardır. Mantarların nem içeriğini \% 92.6'dan, \% 10'a indirmek için gerekli kurutma zamanı ortalama 5.56.5 saat olarak bulunmuştur. Gothandapani et al (1997), yaptıkları çalışmada ortalama nem değeri \% 91.4 olan taze mantarları kurutarak \% 11 nem değerine kadar düşürmüşlerdir. Pal \& Chakraverty (1997), 45, 50 ve $60{ }^{\circ} \mathrm{C}$ kurutma havası sicaklığ 1 ve 0.9 ve $1.6 \mathrm{~m} \mathrm{~s} \mathrm{~s}^{-1}$ hava hızı koşullarında ön işlemin mantarın kuruma karakteristiklerine ve bunların kaliteye etkilerini belirledikleri bir çalışma yapmışlardır. Kuruma süresi ve kalite dikkate alındığında $50{ }^{\circ} \mathrm{C}$ kurutma havası sıcaklığı ve 0.9 $\mathrm{m} \mathrm{s}^{-1}$ hava hızında hem ön işlem görmüş hem de görmemiş mantarlar için iyi kalitede kuru ürünler sağlanabileceğini belirtmişlerdir. Helvacı et al (1999) mantar kurutulması için bazı pratik önerilerde bulunmuşlardır. Mantar dilimlerinin kuruma sonuna doğru, nem içeriklerindeki azalma nedeniyle yüzey sıcaklığının hızla arttığını belirtmişlerdir. Ayrıca yüzey sıcaklığındaki artma, karamelizasyon ve Maillard reaksiyonlarının hızını da arttıracağından, mantar dilimlerinin kurutucu içinde uzun süre kalmaları halinde renklerinin hızla koyulaşacağını belirtmişlerdir. Mantarları, Midilli et al (1999) laboratuar tipi bir kurutucuda, Toğrul et al (2005) infrared kurutucuda, Xanthopoulos et al (2007) ince katmanlı kurutucuda, Lidhoo et al (2008) mantar dilimlerini haşlayarak ve Kulshreshtha et al (2009) akışkan yataklı bir kurutucuda sıcak hava kullanarak kurutmuşlardır. Jambrak et al (2007) tarafından yapılan çalışmada $9.7 \mathrm{~g}$ nem (g kuru 
madde) $)^{-1}$ değerlerine sahip Agaricus biosporus türü mantarlar $0.4 \mathrm{~g}$ nem (g kuru madde) $)^{-1}$ değerlerine düşürülmüştür. Bala et al (2009) güneş enerjili tünel kurutucusunda yaptıkları deneylerde, mantarlar 37 ${ }^{\circ} \mathrm{C}$ 'den $66.5^{\circ} \mathrm{C}$ 'ye kadar kurutma odası sicaklığında kurutulmuş ve nem içeriği yaklaşık \% 89.41'den \% 6.14'e kadar düşürülmüştür. Aynı kuruma döneminde geleneksel güneşte kurutma metoduyla, mantarların nem içeriği \% 15'e kadar azalmıştır.

Genellikle bir sürecin ya da sistemin davranışını tanımlayan denklemlerden oluşan matematiksel modelleme bir takım kolaylık sağlar. $\mathrm{Bu}$ nedenle pek çok alanda kullanıldığ gibi tarım alanında da kullanılmaktadır. Örneğin, Alibaş (2012) mikrodalga kurutucuda kuruttuğu asma yapraklarının bazı kalite parametrelerini belirlemede, Doymaz (2013) ise infrared kurutucuda havuç posası kurutma karakteristiklerini belirlemede kullanmıştır. Biyolojik sinir sisteminden esinlenen YSA modelleri bütün enerji sistemlerinde çok kullanılmaktadır. Son yıllarda da kurutma sistemlerinin YSA ile modellenmesi araştırmacılar tarafindan kullanılmaktadır. Palancar et al (2001) ve Satish \& Pydi Setty (2005) akışkan yataklı bir kurutucunun, Hussain et al (2002) sicak hava kurutucusunun, Erenturk et al (2004) ince tabaka kurutucunun, Poonnoy et al (2007) mikrodalga kurutucusunun, Menlik et al (2009) ve Menlik et al (2010) dondurarak kurutmanın, Karimi et al
(2012) laboratuar kurutucusunun Aghbashlo et al (2012) sprey kurutucunun YSA ile modellemesini yapmışlardır. Benzer olarak, kuruma davranışlarını tanımlamak için YSA ile yaban mersini (Chen et al 2001), pirinç (Zhang et al 2002), cassava ve mango (Hernandez-Perez et al 2004), kereste (Wu \& Avramidis 2006), domates (Movagharnejad \& Nikzad 2007), fistık (Omid et al 2009; Balbay et al 2011), elma (Khoshhal et al 2010), üzüm (Cakmak \& Yildiz 2011) ve havuç (Erenturk \& Erenturk 2007; Nazghelichi et al 2011) gibi farklı ürünlerin de modelleme çalışmaları yapılmıştır. YSA modellemesi yapılan bazı 1s1 pompalı sistemler Çizelge 3'te detaylandırılmıştır.

Görüldüğü üzere birçok araştırmacı farklı sistem ve farklı ürünler için YSA ile modellemeyi kullanmışlardır. Bununla birlikte, literatürde GDIP sisteminin veya bu tarz bir kurutucuda mantar kurutmanın modellenmesi ile ilgili bir çalışma bulunmamaktadır. $\mathrm{Bu}$ noktadan hareketle, enerji verimliliğini göz önünde bulundurarak uygun psikrometrik şartlarda mantarları kurutmak, programlanabilir lojik kontrollü GDIP bir kurutma sisteminin performansını test etmek ve araştırmacılar için kaynak oluşturacak geniş bir literatür ile birlikte kurutucuda mantar kurutma deney sonuçları analiz edilerek MC, MR ve DR'nin YSA ile modellenmesi amaçlanmıştır.

\section{Çizelge 3- YSA ile ilgili ısı pompalı bazı çalışmaların detayları}

Table 3-Details of some studies related to ANN

\begin{tabular}{|c|c|c|c|c|c|c|c|}
\hline \multirow{2}{*}{ Yazarlar } & \multicolumn{6}{|c|}{ YSA modelleri } & \multirow[b]{2}{*}{ Çıkış değerleri } \\
\hline & Sistem & Ürün & Hibrid & $L M$ & Fermi & Giriş değerleri & \\
\hline Ceylan \& Aktaş 2008c & IP & Findik & -- & $\sqrt{ }$ & $\sqrt{ }$ & $T, B N, t$ & $M C, v$ \\
\hline $\begin{array}{l}\text { Esen et al 2008; Esen ve } \\
\text { Inallı } 2009\end{array}$ & TKIP & -- & -- & $\sqrt{ }$ & -- & $\begin{array}{l}\text { Farklı } \\
\text { noktalardaki } \\
\text { sicaklıklar }\end{array}$ & $C O P$ \\
\hline Mohanraj et al 2009 & DGGDIP & -- & -- & $\sqrt{ }$ & -- & $\begin{array}{l}\text { Güneş 1şınımı, } \\
\text { çevre sıcaklığ1 }\end{array}$ & $\begin{array}{l}\text { Güç tüketimi, 1sıtma } \\
\text { kapasitesi, enerji } \\
\text { performans oranı, komp. } \\
\text { deşarj sıcaklığ1 }\end{array}$ \\
\hline Bu çalışma & $\begin{array}{l}\text { GE ve } \\
\text { GDIP }\end{array}$ & Mantar & -- & $\sqrt{ }$ & $\sqrt{ }$ & $\begin{array}{l}T, B N, v, t \text {, güneş } \\
\text { 1şınımı }\end{array}$ & $M C, M R, D R$ \\
\hline
\end{tabular}




\section{Materyal ve Yöntem}

\subsection{Deneysel çalışma}

Deney düzeneği, iki sistemin ayrı ayrı veya birlikte kullanılabilmesine olanak sağlamaktadır. Sistem, gaz (soğutucu akışkan), su ve hava devresi olmak üzere üç akışkan devresinden oluşmaktadır (Şekil 1). Sistem, üç senaryoya hizmet etmekle birlikte bu çalışmada iki senaryo ele alınmıştır. Birinci senaryoda; sadece güneş enerjisi sistemi devrededir. Güneş enerjisinden elde edilen 1s1 enerjisinin kurutma için yeterli olması durumudur. $\mathrm{Bu}$ durumda sistemde sadece 1sitma yapılır, nem alma işlemi yapılmaz. Kolektörlerde fazladan 1S1 üretilmesi halinde üretilen 1S1, 1s1 depolama tankına yönlendirilmektedir. İkinci senaryoda ise; hem güneş enerjisi hem de kondenzasyonlu (nem almalı) 1S1 pompası sistemi devrededir. Güneş enerjisinden elde edilen isinın yetersiz olması durumunda is1 pompası devreye girmekte, yeterli olması halinde devreden çıkmaktadır. Güneş enerjisinden ve/veya 1s1 pompas1 kondenserinden elde edilen 1s1 enerjisi frekans konvektörlü olan ve sicaklığa göre hız kontrolü yapılabilen bir fan yardımıyla kurutma odasına verilmektedir.

GDIP kurutma sistemi: güneş kolektörü (düzlemsel, tek camlı, $2 \mathrm{~m}^{2}$ ), sirkülasyon pompası $1\left(0.37 \mathrm{~kW}, 5-40 \mathrm{~L} \mathrm{~min}^{-1}\right)$, sirkülasyon pompası 2 $(0.04-0.09 \mathrm{~kW})$, fan $1(0.37 \mathrm{~kW})$, fan $2(0.06 \mathrm{~kW})$, solenoid valf ( 1 " ve $3 / 4$ ", $0.5-16$ bar, $-20+80{ }^{\circ} \mathrm{C}$, $220 \mathrm{~V}$ ), genleşme tank1 (24 L), kompresör (hermetik $1.1 \mathrm{~kW}-1.5 \mathrm{HP}$ ), soğutucu akışkan (R404A), kondenser 1 (hava soğutmalı $1260 \mathrm{kcal} \mathrm{h}^{-1}$ ), kondenser 2 (hava soğutmal $1500 \mathrm{kcal} \mathrm{h}^{-1}$ ), evaporatör (su soğutmalı), kurutucu filtre (dryer), kılcal boru, VAV kutusu (5 VA, 3W, AC/DC $24 \mathrm{~V}, 50 / 60 \mathrm{~Hz}$ ), dijital sicaklık kontrolör (PC440, 100-240 V) ve transformatör (EI-7635, $24 \mathrm{~V}-220 \mathrm{~V}, 50 \mathrm{VA}, 50 / 60$ $\mathrm{Hz}$ ) gibi ana ekipmanlardan oluşmaktadır. Sistemin otomasyon ünitesi ise invertör (VFD-ED, 0.1-

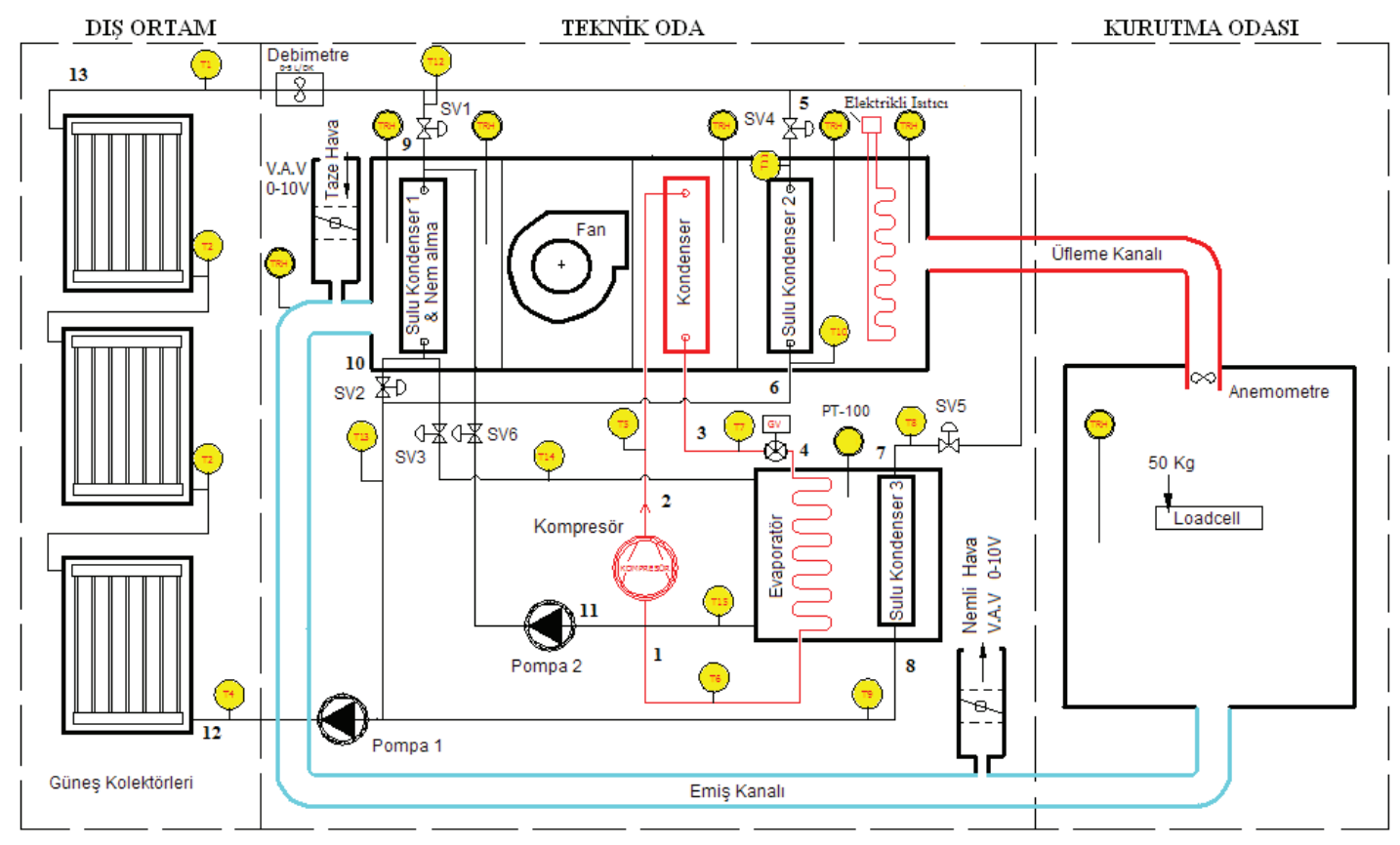

Şekil 1- Güneş destekli ısı pompalı kurutucu

Figure 1-Solar-assisted heat pump dryer 
$600 \mathrm{~Hz}, 230 \mathrm{~V} 1 \mathrm{faz}, 460 \mathrm{~V} 3 \mathrm{faz}$ ), kontaktör, okuyucu kart, sersör bordu, PLC, şalter vb. ekipmanlar ile kontrol ekipmanları, sıcaklık-nem sensörleri ve verilerin izlenerek kontrolünün yapıldığı bir dizüstü bilgisayardan oluşmaktadır.

Sistemin çeşitli noktalarına farklı amaçlar için ölçüm cihazları yerleştirilmiştir. Sıcaklık ve nem ölçümleri için; nem-sıcaklık sensörleri (HTTD, 0-10 VDC, 15-35 VA/DC, $\left.-50-125^{\circ} \mathrm{C}, 5-95 \% \mathrm{RH}\right)$, Pt-100 sicaklık sensörü (R/T Tip, Skala $0-70{ }^{\circ} \mathrm{C}$, besleme 24 V-DC, çıkış 4-20 mA) ve LM35 sıcaklık sensörleri $\left(-55-150{ }^{\circ} \mathrm{C}, 10 \mathrm{mV}{ }^{\circ} \mathrm{C}^{-1}\right)$ kullanılmıştır. Diğer ölçüm ve kontrol elemanları ise, hava hızı ölçüm cihazı $\left(0-20 \mathrm{~m} \mathrm{~s}^{-1}\right.$, hassasiyet $\pm 0.01 \mathrm{~m} \mathrm{~s}^{-1}, 0.1$ ${ }^{\circ} \mathrm{C}$, teleskobik kanal probu), ağırlık ölçer (kapasite $50 \mathrm{~kg}$, hassasiyet $2.0 \mathrm{mV} \mathrm{V}^{-1}$ ), basınç transmitteri (0-10 bar, çıkış 4-20 mA) ve kontrol kartları (30 adet sıcaklık ve nem sensörü bağlanabilir, 8 analog giriş, 8 dijital giriş, 4 analog çıkış $0-10 \mathrm{~V}, 6$ role ve 2 adet SSR) gibi ekipmanlardan oluşmaktadır. Güneş 1şınımı değerleri dijital solarimetre (DS$05 \mathrm{~A}, 0-1200 \mathrm{~W} \mathrm{~m}^{-2}$, hassasiyet $\pm \% 3 \mathrm{~W} \mathrm{~m}^{-2}$ ) ile ölçülmüştür.

Sistemde, güneş kolektöründen elde edilen uygun sıcaklıktaki su, 1s1 pompasının 1sı kaynağı olarak kullanılmaktadır. Su kaynaklı bir 1 s1 pompası sistemi ile 1sı değiştiricili bir güneş enerjisi sisteminin birlikte kullanılmasıly kurutma işlemleri gerçekleştirilebilmektedir. Kurutma sisteminde gerekli toplam 1sı miktarı, 1s1 pompasının kondenseri ve güneş enerjisi ile sağlanmaktadır. Tasarlanan sistem ile 1sı enerjisi üretilerek ürün kurutulması gerçekleştirilebilmekte ve aynı zamanda da elde edilen 1s1 enerjisinin depolanması gerçekleştirilebilmektedir. Sistemde 1sı depolaması, kullanılan kolektör miktarına yani toplam kolektör alanına göre tayin edilmiş ve kolektörlerden elde edilen sıcak suyun toplandığı 1sı depolama tankında yapılmaktadır. Nem yönünden fakir (kuru) havanın daha çabuk isınacağ 1 ve nemli havanın nemini alarak nem alma kapasitesinin artırılabileceği düşünülerek dönüş havasının nemini çekebilmek için sisteme nem alma ünitesi eklenmiştir. Isı pompası devredeyken nem alma işlemi, soğuk suyun nem alma bataryasında dolaştırılması ile gerçekleştirilmektedir. Nemi alınan ve sıcaklığı düşen havan, güneş enerjisi ve IP'nın kondenseri ile tekrar isitılmaktadır.

Sistem, temel olarak üç kısımdan oluşmaktadır; 1S1 üreticisi (güneş enerjisi devresi), 1sı sağlayıcı (1S1 pompası sistemi) ve 1s1 aktarıc1 (fan veya devirdaim pompas1). Sistemde gaz-hava, gaz-su-hava, su-hava şeklinde birleşimler oluşturulabilmektedir. Güneş kolektörlerinde 1sı taşıyıcı akışkan olarak \% 40 glikollü su kullanılmıştır. Karışım bu haliyle yaklaşık $-25^{\circ} \mathrm{C}$ sıcaklığa kadar koruma sağlamaktadır. Buhar sıkıştırmalı çevrime göre çalışan gaz devresi iş gören akışkan olarak R 404A kullanılmaktadır.

Sistemde kontrol işlevi; kontrol elemanları, sistemin yönlendirilmesinde kullanılan ölçü aletleri ile senkronize çalışan kontrol kartları, sistem yazılımı ve benzeri ekipmanların birbiriyle uyumlu kullanıldığ1 bir dizi elektro-mekanik kontrol elemanları tarafından sağlanmaktadır. Sistem, havanın sıcaklık ve nem kontrolünün anlık olarak bilgisayar ekranından takibine ve kontrolüne imkân vermektedir. Deneyler sirasında da bütün kontroller bilgisayar ekranından yapılmıştır. Böylece, sistemde kurutma havası şartları, PLC ekranından set edilen değerlerde sağlanabilmiştir.

\subsection{Sistemin analizi}

Sistemin enerji ve kurutma analizlerinde kullanılan bazı genel eşitlikler aşağıda verilmiştir. Isı pompası çevriminin $\log \mathrm{P}-\mathrm{h}$ diyagramı ise Şekil 2'de verilmiştir. Kullanılan soğutucu akışkanın $\log \mathrm{P}-\mathrm{h}$ diyagramında; $h_{2}-h_{1}$ kompresör çıkış girişini, $h_{2}-$ $\mathrm{h}_{3}$ kondenser giriş çıkışını, $\mathrm{h}_{3}=\mathrm{h}_{4}$ genleşme valfi giriş çıkışını ve $h_{4}-h_{1}$ evaporatör giriş çıkışını ifade etmektedir.

Şekil 2'den görüldüğü üzere 1S1 pompas1 sisteminde kondenser kapasitesi;

$\dot{Q}_{K}=\dot{m}\left(h_{2}-h_{3}\right)$

Kompresör gücü;

$\dot{Q}_{C}=\dot{m}\left(h_{2}-h_{1}\right)$

Evaporatör kapasitesi ise;

$\dot{Q}_{E}=\dot{m}\left(h_{1}-h_{4}\right)$ 


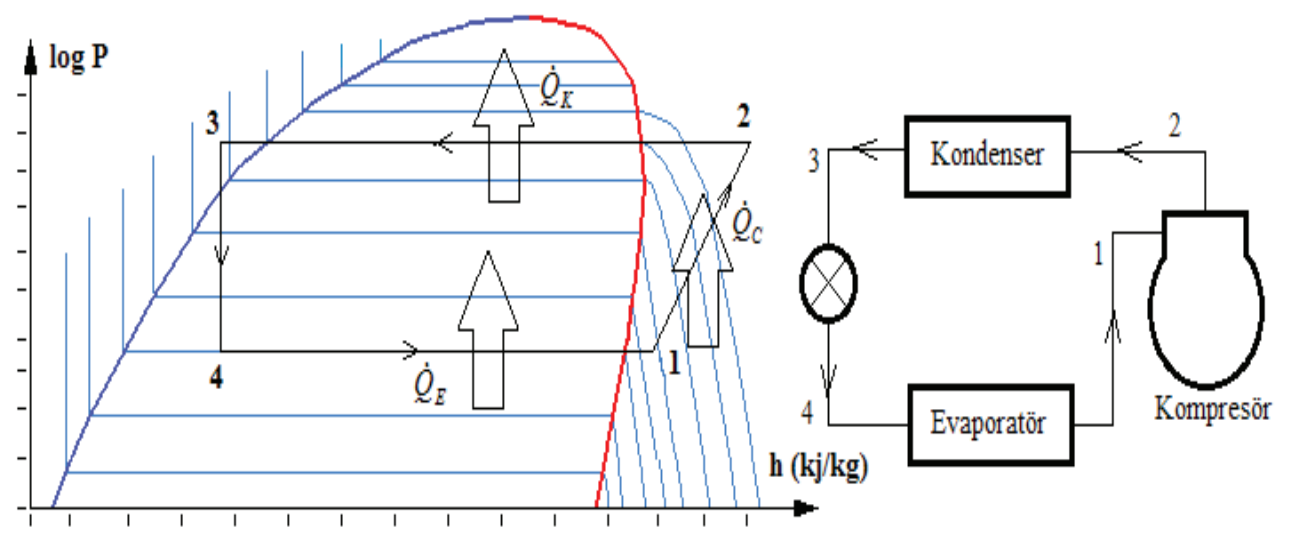

Şekil 2- Isı pompası çevriminin logP-h diyagramı

Figure 2- LogP-h diagram of heat pump cycle

ile hesaplanmıştır. Nemin çekilmesi için kurutma odasinda kullanılan 1sı miktarı;

$\dot{Q}_{K O}=\dot{m}_{i a}\left(h_{i a}-h_{o a}\right)$

eşitliği ile hesaplanmıştır. Güneş kolektöründen birim zamanda elde edilen enerji;

$\dot{Q}=\dot{m} . c . \Delta T$

ile ve güneş kolektörünün verimi ise;

$\eta_{k o l}=\frac{\dot{Q}}{F_{K} I_{T O P}}$

eşitliği ile hesaplanmıştır (Aktaş et al 2012). Isı pompasının performans katsayıs1;

$C O P_{I P}=\frac{\dot{Q}_{K}}{\dot{Q}_{C}}$

yardımıyla elde edilmiştir. Güneş enerjisi destekli 1S1 pompas1 sisteminin performans katsayıs1 ise;

$C O P_{\text {sist }}=\frac{\dot{Q}_{\text {sist }}}{\dot{W}_{\text {sist }}}=\frac{\dot{Q}_{\text {sist }}}{\dot{Q}_{C}+\Sigma \dot{W}_{F a n}+\Sigma \dot{W}_{\text {pomp }}}$

eşitliğinden yararlanılarak elde edilmiştir. Mantarlardaki kuru esasa göre nem içeriği $\left(M C_{K A}\right)$ değerleri için;

$M C_{K A}=\frac{Y A-K A}{K A}$ eşitliği, yaş esasa göre nem içeriği $\left(M C_{Y A}\right)$ değerleri için ise;

$M C_{Y A}=\frac{Y A-K A}{Y A}$

eşitliği kullanılmıştır. Ayrılabilir nem oranı (MR) değerleri;

$M R=\frac{M-M_{e}}{M_{0}-M_{e}}$

ile hesaplanmıştır. Kurutma hızı $(D R)$ değerleri aşağıdaki formülden hesaplanmıştır.

$D R=\frac{M_{t+d t}-M_{t}}{d t}$

\subsection{Yapay sinir ăglart}

Yapay sinir ağları, biyolojik sinir sisteminin çalışma şeklinin yapay olarak benzetimidir. Yapay olarak oluşturulan bu ağlar insanoğlunun yaşayarak ve deneyerek sahip olduğu öğrenme yeteneğinde olduğu gibi bilgiyi öğrenir, saklar ve veriler arasındaki ilişkiyi ortaya çıkarır. Şekil 3'te basit bir nöron yapısı görülmektedir. Bu basit yapı yapay nöron için bir model oluşturur. Nöronlar arasındaki sinaptik bağlantıların ayarlanması ile insanoğlunda öğrenme olur. Nöronlar giriş uyarısını çok sayıda dentritleri vasıtasıyla alır. Dentritlerce 
alınan bir giriş, harekete geçirici (tetikleyici) veya yasaklayıcı olabilir. Girişler toplanır ve nöron gövdesine yerleştirilir. $\mathrm{Bu}$ girişler, belirli bir eşik değerini aştığı zaman, hücre diğer hücrelere aksonu vasıtasıyla bir etki iletir. Yapay sinir ağları da aynı mantıkla hareket edilerek meydana getirilmiş matematiksel sistemlerdir. Oluşturulan yapay sinir ağları eğitilmelidir ancak kendi kendilerine öğrenme yapısına sahip olduklarından bazı ağların eğitilmesine gerek yoktur (Jang et al 1997; Sözen et al 2003).

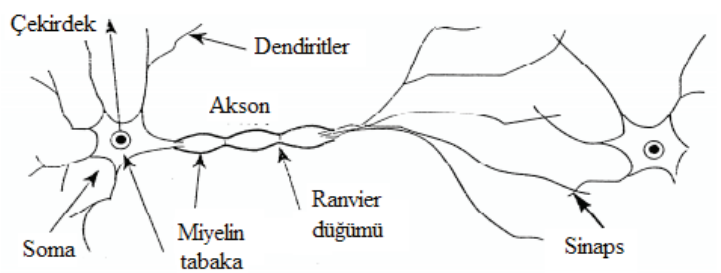

Şekil 3- Basit bir nöron yapısı

Figure 3- A simple structure of the neuron

Yapay sinir ağı; giriş katmanı, bir veya daha çok ara (gizli) katman, çıktı katmanı ve bu katmanlar arasındaki yapay sinir hücrelerinin bir araya gelmesiyle oluşur. Yapay sinir ağları meteoroloji, mühendislik, tıp, ekonomi, enerji ve tarım gibi pek çok alanlarda karmaşık sorunları çözmek için araştırmacılara alternatif bir yol sunmaktadır. Günümüzde tarımda, özellikle arazi, gıda, otomasyon, ekim, güneş radyasyonu, sulama ve yeraltı suları gibi uygulama alanlarında yüksek hızda tahminler gerçekleştirilmesinde YSA başarıyla kullanılmaktadır.

Geliştirilen YSA modeli, sinir ağları geliştirme ve tasarım için tasarlanmış bir program olan Pythia programı kullanılarak modellenmiştir. Pythia programı, parçacık hızlandırıcılarında çok yüksek enerjilerde parçacık çarpışmaları için kullanılan bir bilgisayar simülasyon programıdır. Başlangıçta Fortran ile yazılan Pythia programının 8.1 sürümü $\mathrm{C}++$ ile yazılmıştır. Pythia Microsoft Excel gibi elektronik tablo programlarından veya farklı dosya formatlarından veri almak için izin verir. İstatistiksel analizler için ideal bir program olan
Pythia günümüzde farklı alanlarda yapay zeka elektronik simülasyonları için kullanılmaktadır. $\mathrm{Bu}$ çalışmada, deneylerden elde edilen nem içeriği (MC), ayrılabilir nem oranı (MR) ve kurutma hızı (DR) değerleri için Levenberg-Marquardt (LM) geri yayılım öğrenme algoritması ve Fermi transfer fonksiyonu kullanılmıştır.

Model değerlendirmede gerçek değerlerle tahmin edilen değerleri kıyaslayabilmek için çoklu belirleme katsayısı $\left(\mathrm{R}^{2}\right)$, ortalama hata kareleri karekökü (RMSE) ve ortalama mutlak hata yüzdesi (MAPE) gibi istatistiksel metotlar kullanılır. YSA modelleri için $\mathrm{R}^{2}$ 'nin 1 'e yaklaştığ 1 ve daha küçük RMSE ve MAPE değerleri en iyi modeli verir (Menlik et al 2010). $\mathrm{R}^{2}$, RMSE ve MAPE parametreleri aşağıdaki eşitlikler kullanılarak hesaplanmıştır.

$$
R^{2}=1-\left[\frac{\sum\left(M C_{\mathrm{exp}, i}-M C_{A N N, i}\right)^{2}}{\sum\left(M C_{A N N, i}\right)^{2}}\right]
$$

$R M S E=\left[\frac{1}{N} \sum_{i=1}^{N}\left(M C_{A N N, i}-M C_{\text {exp }, i}\right)^{2}\right]^{1 / 2}$

$M A P E=\frac{M C_{A N N}-M C_{\text {exp }}}{M C_{A N N}} 100$

Pythia programında veriler (0-1) aralığında normalize edilerek kullanılır. Girdi ve çıktı verilerini (0-1) aralığında normalize etmek için aşağıdaki eşitlik kullanılmıştır.

$V_{N}=\frac{V_{R}-V_{\min }}{V_{\max }-V_{\min }}$

Burada, $\mathrm{V}_{\mathrm{N}}$ gerçek değer $\mathrm{V}_{\text {min }}$ ve $\mathrm{V}_{\max }$ ise minimum ve maksimum değerleri ifade eder.

\subsection{YSA'nin uygulanmast}

Deneyler, $45^{\circ} \mathrm{C}$ ve $55^{\circ} \mathrm{C}$ kurutma havası sıcaklığında $0.9 \mathrm{~m} \mathrm{~s}^{-1}$ ve $1.2 \mathrm{~m} \mathrm{~s}^{-1}$ hava hızında gerçekleştirilmiştir. Pal ve Chakraverty (1997) kuruma süresi ve kalite dikkate alındığında $50{ }^{\circ} \mathrm{C}$ kurutma havası sıcaklığı ve $0.9 \mathrm{~m} \mathrm{~s}^{-1}$ hava hızında hem ön işlem görmüş hem de görmemiş mantarlar için iyi kalitede kuru ürünler sağlanabileceğini belirttiğinden yola çıkılarak 
sistemde deneyler için bu değerler seçilmiştir. Mantarlar; sadece güneş enerjisi ve güneş destekli 1S1 pompası kullanılarak yaş baza göre \% 93 nem içeriğinden $\% 7$ nem içeriğine kadar kurutulmuştur.

Deneyler sırasında güneş enerjisi kullanılarak yapılan veya güneş enerjisiyle başlanılan deneylerde kurutma odasında istenilen sıcaklığa çok çabuk (10-15 dakikada) ulaşılmasına rağmen 1S1 pompası ile başlanılan deneylerde kurutma odasında istenilen sıcaklığa yaklaşık 1 saat gibi uzun bir sürede ulaşılmıştır. Fakat güneş enerjisi kullanılarak başlanan deneylerde sistem çok hızlı denge konumuna gelmesi bir avantaj olmakla birlikte nem alma ünitesinin çalışmıyor olması da (1s1 pompası çalıştığı sürece nem alma ünitesi de çalışmaktadır) bir dezavantaj oluşturmuştur. Yani, GDIP sisteminin GE sistemine göre avantaj1 1s1 pompasının çalışmasına göre nem alma işleminin de yapiliyor olmasidir. Sistemde $45{ }^{\circ} \mathrm{C}$ ve $55^{\circ} \mathrm{C}$ kurutma odası sıcaklığı için yapılan deneylere ait zamana bağlı MC, MR ve DR değerleri Eşitlikler 9, 11 ve 12 'den hesaplanmış ve GI değerleri dijital solarimetre ile ölçülmüştür. Yapılan hesaplama ve ölçümlere göre oluşturulan grafikler Şekil 4 ve Şekil 5'te verilmiştir. Ayrıca, sistemin kolektör verimi Eşitlik 6'dan \% 45-55 ve tüm sistemin $\mathrm{COP}_{\text {sist }}$ değeri Eşitlik 8'den 2.2-3.1 hesaplanmıştır. Eşitliklerden hesaplanan değerler ile grafiklerde verilen değerler literatürdeki çalışmalarla karşılaştırıldığında benzer sonuçlar elde edildiği görülmektedir.

Elde edilen deneysel sonuçlar sayesinde Pythia programı kullanılarak 5 adet giriş, 3 adet çıkış değerlerine sahip çok katmanlı bir sinir ağı algılayıcısı modeli oluşturulmuştur. Ağ için giriş verileri olarak; zaman (t), kurutma havası hızı (v), kurutma havası sicaklığı (T), kurutma havası bağıl nemi (BN) ve güneş 1şınımı (GI) değerleri kullanılmıştır. Çıkış verileri olarak; nem içeriği (MC), ayrılabilir nem oranı (MR) ve kurutma hızı
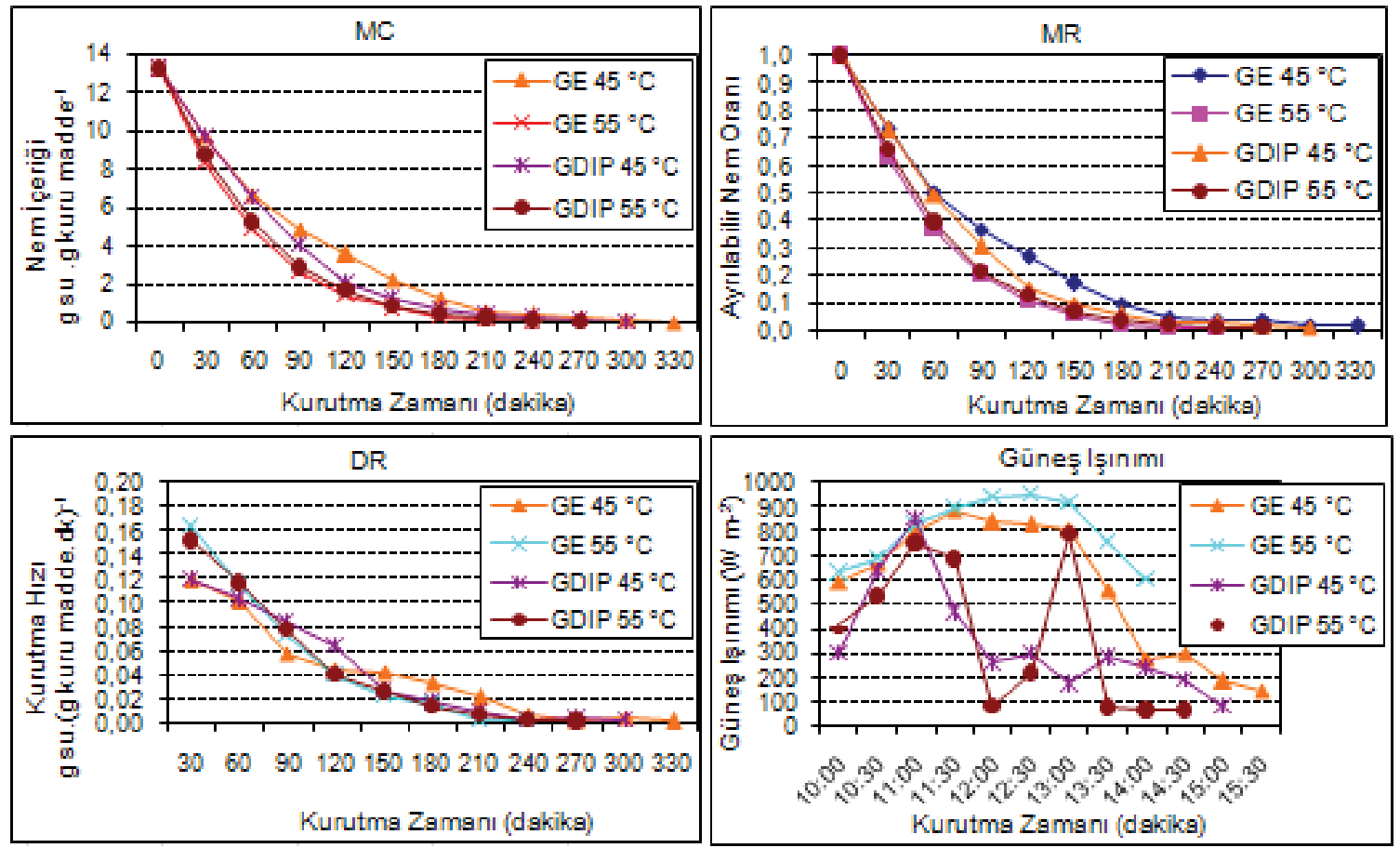

Şekil 4- 0.9 m s s $^{-1}$ kurutma havası için MC, MR, DR ve GI değerleri

Figure 4-MC, MR, DR and SR values for $0.9 \mathrm{~m} \mathrm{~s}^{-1}$ drying air velocity 

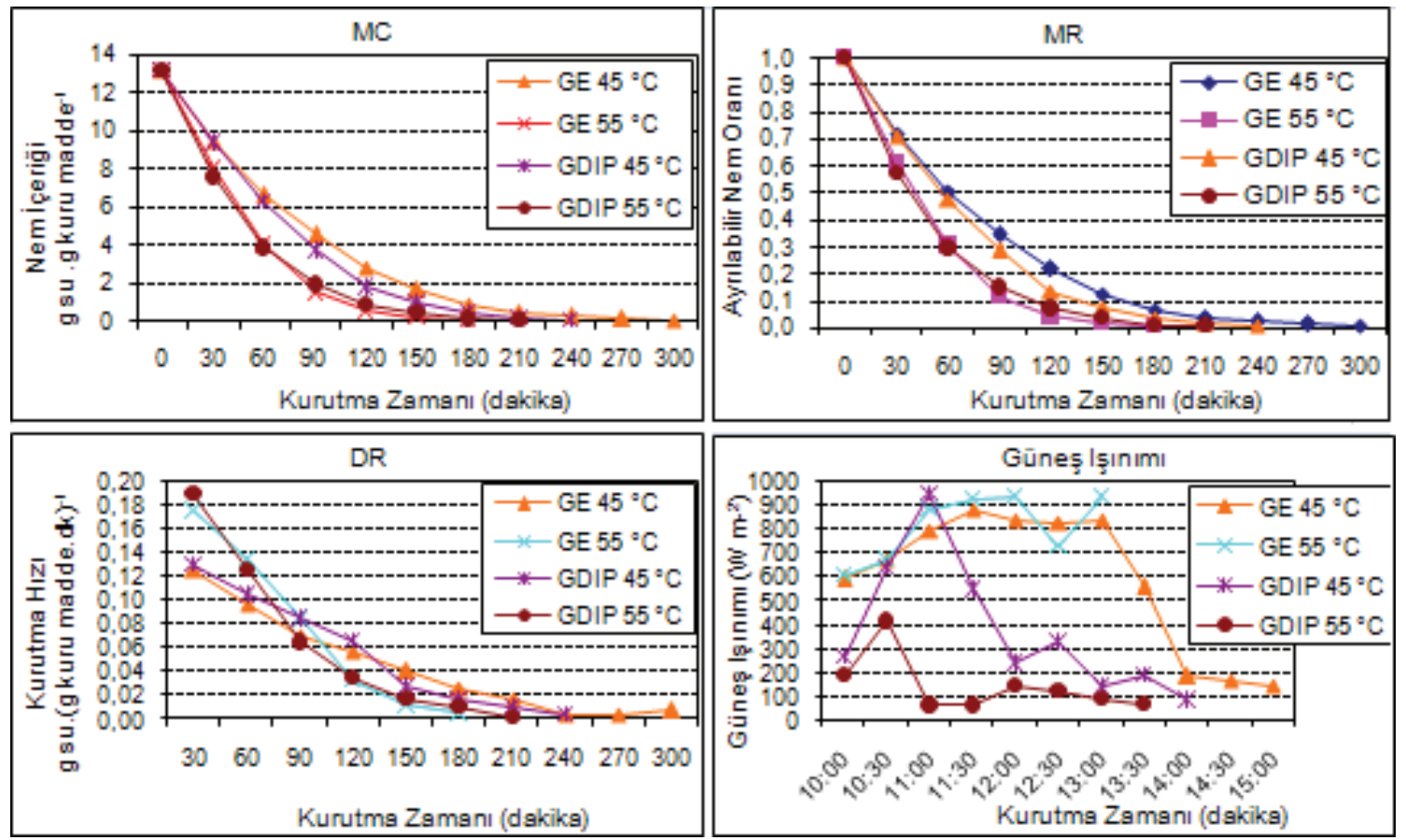

Şekil 5- $1.2 \mathrm{~m} \mathrm{~s}^{-1}$ kurutma havası için MC, MR, DR ve GI değerleri

Figure 5-MC, MR, DR and SR values for $1.2 \mathrm{~m} \mathrm{~s}^{-1}$ drying air velocity

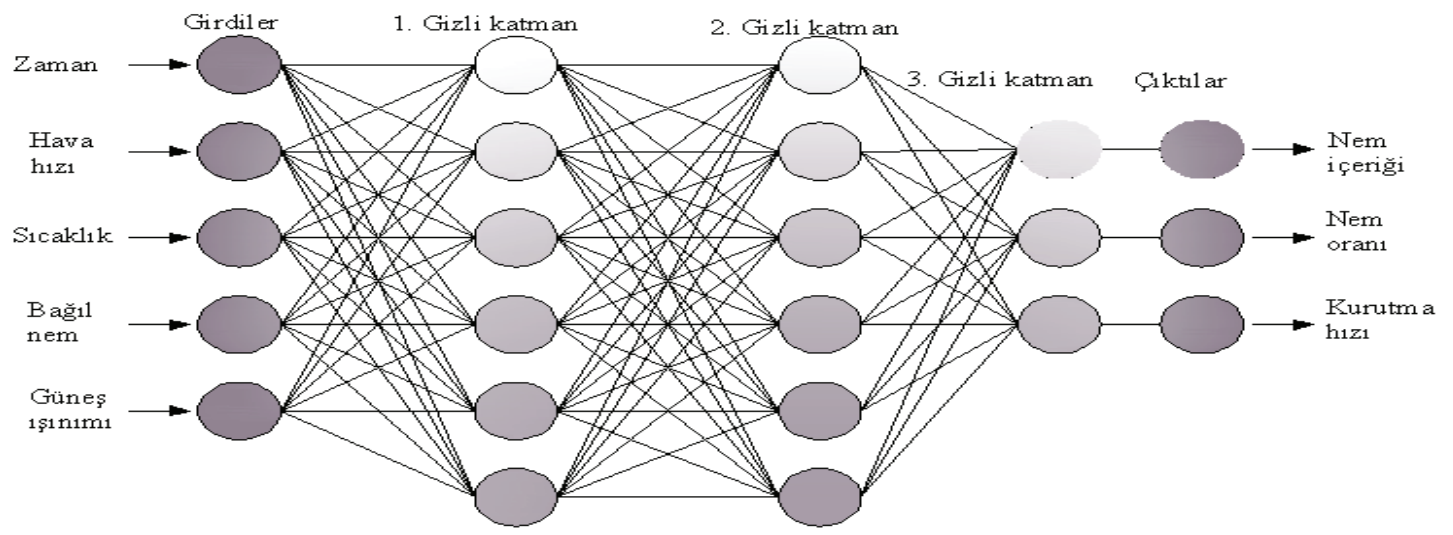

Şekil 6- Modellemede kullanılan YSA yapısı

Figure 6- YSA structure used in modeling

(DR) değerleri kullanılmıştır. Ara katman olarak ise; üç gizli katman oluşturulmuş ve ara katman sayısı değiştirilerek en iyi çözümler elde edilmeye çalışılmıştır. YSA modellemesinde geri yayılım öğrenme algoritması olarak Levenberg-Marquardt (LM) kullanılmıştır. Oluşturulan YSA modelinin yapısı Şekil 6'da verilmiştir. 


\section{Bulgular ve Tartışma}

YSA modellemesinde toplam 77 adet veri kullanılmıştır. $\mathrm{Bu}$ verilerden 69 tanesi eğitim için 8 tanesi ise test için kullanılmıştır. YSA modellenmesinde aşağıda eşitliği verilen FERMI transfer fonksiyonu kullanılmıştır. Burada, z girdi ağırlıklarının toplamıdır.

$$
F(z)=\frac{1}{1+e^{-4(z-0.5)}}
$$

Üç gizli katmana sahip 15 nöronlu LM algoritması olan MC, MR ve DR'ye ait çıktıları elde etmek için Eşitlik 17 kullanılarak aşağıdaki eşitlikler oluşturulmuştur.

$$
\begin{aligned}
& f_{M C}=\frac{1}{1+e^{-4 \cdot\left(0,655660 \cdot F_{1}-0,221305 \cdot F_{2}+3,229919 \cdot F_{3}-1,854275 \cdot F_{4}+1,153900 \cdot F_{5}+0,003321 \cdot F_{6}-0.5\right)}} \\
& f_{M R}=\frac{1}{1+e^{-4 \cdot\left(0,656238 \cdot F_{1}-0,222690 \cdot F_{2}+3,249601 \cdot F_{3}-1,833049 \cdot F_{4}+1,134295 \cdot F_{5}+0,020944 \cdot F_{6}-0.5\right)}} \\
& f_{D R}=\frac{1}{1+e^{-4 \cdot\left(0,490989 \cdot F_{1}+1,021071 \cdot F_{2}-5,221842 \cdot F_{3}-1,02127 \cdot F_{4}+2,624680 \cdot F_{5}-0,888774 \cdot F_{6}-0.5\right)}}
\end{aligned}
$$

Eşitlikler $18-20$ 'deki $F_{1}, F_{2}, F_{3}, F_{4}$ ve $F_{5}$ ve $F_{6}$ değişkenleri aşağıdaki eşitlik ile hesaplanmıştır.

$F_{i}=\frac{1}{1+e^{-4\left(E_{i}-0.5\right)}}$

Formüldeki $E_{i}$ değişkenleri aşağıdaki eşitlik ile hesaplanmıştır.

$$
E_{i}=L_{1 i} \cdot N_{1}+L_{2 i} \cdot N_{2}+L_{3 i} \cdot N_{3}+L_{4 i} \cdot N_{4}+L_{5 i} \cdot N_{5}+L_{6 i} \cdot N_{6}
$$

Formüldeki $N_{1}, N_{2}, N_{3}, N_{4}, N_{5}$ ve $N_{6}$ değişkenleri aşağıdaki eşitlik ile hesaplanmıştır.

$$
N_{i}=\frac{1}{1+e^{-4\left(C_{i}-0.5\right)}}
$$

Formüldeki $C_{i}$ değişkenleri aşağıdaki eşitlik ile hesaplanmıştır.

$$
C_{i}=Z_{1 i} \cdot \mathrm{t}+Z_{2 i} \cdot \mathrm{u}+Z_{3 i} \cdot \mathrm{T}+Z_{4 i} \cdot N+Z_{5 i} \cdot \mathrm{GI}
$$

Eşitlik 22 ve 24'te kullanılan sabit değerler Çizelge 4 ve Çizelge 5 'ten alınmıştır.

Giriş ve çıkış verileri $(0,1)$ aralığında Eş. 16 kullanılarak normalize edilmiştir. Normalizasyon için kullanılan ilgili değişkenin minimum ve maksimum değerleri olan $\mathrm{V}_{\min }$ ve $\mathrm{V}_{\max }$ değerleri Çizelge 6'da verilmiştir. Böylece, kurutmada önemli parametreler olan MC, MR ve DR'yi belirleyebilmek için $\mathrm{t}, \mathrm{T}, \mathrm{v}, \mathrm{BN}$ ve GI girdi değerlerine ve $\mathrm{MC}, \mathrm{MR}$

\section{Çizelge 4- Eşitlik 22'de kullanılan sabitler}

Table 4-Constants used in Equation 22

\begin{tabular}{lllllll}
\hline \multirow{2}{*}{$\dot{I}$} & \multicolumn{7}{c}{ Sabit değerler } \\
\cline { 2 - 7 } & \multicolumn{1}{c}{$L_{l i}$} & \multicolumn{1}{c}{$L_{2 i}$} & \multicolumn{1}{c}{$L_{3 i}$} & \multicolumn{1}{c}{$L_{4 i}$} & \multicolumn{1}{c}{$L_{5 i}$} & \multicolumn{1}{c}{$L_{6 i}$} \\
\hline 1 & -2.321527 & 0.590711 & 0.069522 & 1.759852 & 0.520794 & 0.538123 \\
2 & -0.930626 & 0.096047 & 0.151918 & 0.831941 & 0.291443 & -0.117653 \\
3 & -1.361434 & -0.651064 & -1.564431 & 1.362998 & -0.688603 & -0.55633 \\
4 & 0.008133 & -4.60572 & 0.687421 & -1.400169 & -0.185445 & 0.292951 \\
5 & 0.53251 & -1.347945 & -0.154563 & -0.574236 & -0.943862 & 0.635645 \\
6 & 0.066703 & -1.412604 & 0.156158 & -0.422767 & -0.883376 & -0.965652 \\
\hline
\end{tabular}


Çizelge 5- Eşitlik 24'te kullanılan sabitler

Table 5- Constants used in Equation 24

\begin{tabular}{cccccc}
\hline \multirow{I}{I}{} & \multicolumn{5}{c}{ Sabit Değerler } \\
\cline { 2 - 6 } & $Z_{1 i}$ & $Z_{2 i}$ & $Z_{3 i}$ & $Z_{4 i}$ & $Z_{5 i}$ \\
\hline 1 & 3.791242 & 0.243342 & 0.202915 & -3.022506 & -1.738583 \\
2 & -0.214663 & -0.163685 & -2.037086 & 4.289017 & 1.059204 \\
3 & 1.782738 & 1.797376 & -1.220573 & -2.835265 & -0.58984 \\
4 & -2.801917 & -0.434716 & 2.11357 & 2.975089 & -2.012087 \\
5 & 0.273277 & -0.857089 & 2.998076 & 0.122141 & -2.015587 \\
6 & -3.435122 & 0.254516 & 0.691853 & -0.06891 & 0.53769 \\
\hline
\end{tabular}

Çizelge 6- Normalizasyon için kullanılan $V_{\min }$ ve $\mathbf{V}_{\max }$ değerleri

Table 6- $V_{\min }$ and $V_{\max }$ values used for normalization

\begin{tabular}{lll}
\hline Parametreler & $V_{\min }$ & $V_{\text {max }}$ \\
\hline Zaman & 0 & 330 \\
Sicaklık & 17 & 55.95 \\
Bağıl nem & 8.2 & 74.5 \\
Hız & 0 & 1.2 \\
Güneş ışınımı & 58 & 953 \\
MC & 0.068376 & 13.24501 \\
MR & 0.0067541 & 1 \\
DR & 0 & 0.188034 \\
\hline
\end{tabular}

ve DR çıktı değerlerine sahip üç gizli katman ve 15 nörondan oluşan bir YSA modeli geliştirilmiş oldu. Bu sayede, süreç tahmin modellemesi ve optimizasyonunda kullanılan bu modelin kuruma süreçlerinin kontrolü için uygulanması kolay ve etkili bir hale getirilmiştir.

Ağ öğrenme işlemi başarılı bir şekilde tamamlandığından, elde edilen ağ, öğrenme işlemine dahil edilmeyen test datalarıyla karşılaştırılmıştır. MC, MR ve DR için geliştirilen YSA modelin performans1 Şekil 7-9'da gösterilmiştir. Tahmini değerler ile deneysel değerlerin arasındaki fark çok küçük ve ihmal edilebilir olduğundan değerler arasında bir uyum olduğu görülebilir.

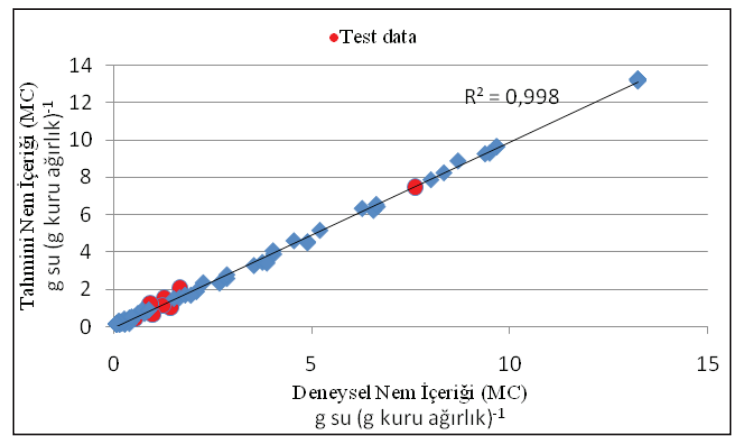

Şekil 7- Deneysel-tahmini nem içeriği değerleri

Figure 7- Experimental-predicted moisture content values

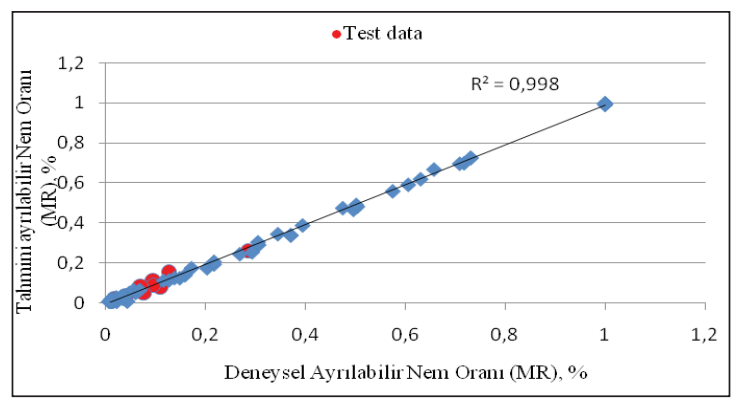

Şekil 8 - Deneysel-tahmini ayrılabilir nem oranı değerleri

Figure 8- Experimental-predicted moisture ratio values 


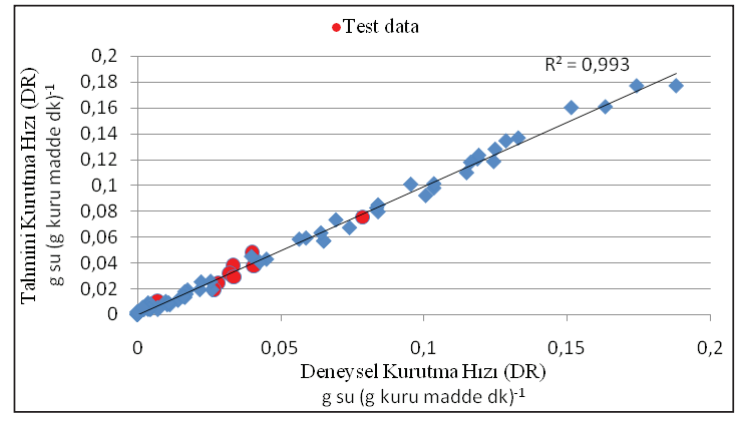

Şekil 9- Deneysel-tahmini kurutma hızı değerleri

Figure 9-Experimental-predicted moisture rate values

Şekil 7-9'dan görüldüğü gibi deneysel veriler ile tahmin edilen veriler uyum içindedir. $\mathrm{Bu}$ sonuçlara göre yapılan modellemenin uygun olduğu görülmektedir. $M C, M R$ ve $D R$ için geliştirilen modelin istatistiksel geçerliliğinin belirlenmesinde kullanılan parametrelerin $R^{2}$, RMSE ve MAPE gibi istatistiksel değerleri Eşitlikler 13-15'ten hesaplanarak Çizelge 7'de verilmiştir.

\section{Çizelge 7- MC, MR ve DR istatistiksel değerleri}

Table 7-Statistical values of $M C, M R$ and $D R$

\begin{tabular}{llll}
\hline & $R^{2}$ & RMSE & MAPE \\
\hline MC & 0.998 & 0.0015608 & 0.1940471 \\
MR & 0.998 & 0.0000971 & 0.2214687 \\
DR & 0.993 & 0.0000075 & 0.8627478 \\
\hline
\end{tabular}

\section{Sonuçlar}

Kullanıcıların tercih edebileceği etkin ve verimli bir sistem deneysel olarak incelenmiş, modellenmiş ve analiz edilmiştir. İklime bağlı kalmadan, bütün yıl boyunca ekonomik olarak ürün kurutulmasına imkân sağlayan bilgisayar kontrollü güneş destekli bir kurutucuda sıcaklık, bağıl nem, ürün ağırlığı ve kurutma şartları kontrol edilerek mantar kurutulmuştur. Pek çok değişken kontrol edilebildiğinden geniş yelpazede farklı ürünlerin kurutulmasinda, 1si gereksinimi duyulan mekan ve sera 1sitması gibi uygulamalarda da kullanılabilme yeteneğine sahip bu sistemde dilimlenmiş mantarlar ortalama 250 dakikada kurutularak MC, MR ve DR değerleri hesaplanmıştır. Güneş kolektörü verimi \% 45-55 aralığında hesaplanırken $\mathrm{COP}_{\text {sist }}$ değeri ise 2.2-3.1 arasında değişmiştir. Sistemdeki cihazların (kompresör, fan, pompa vb.) verimlerinin arttırılması ile ve kurutma verimine etki eden parametrelerin iyileştirilmesi ile sistem performans katsayısı $\left(\mathrm{COP}_{\text {sist }}\right)$ arttırılabilir. $\mathrm{Bu}$ sistem, konvansiyonel kurutuculara iyi bir alternatif olarak görülebilir. Enerji verimliliği, enerjinin etkin kullanımı, çevresel ve otomatik kontrol gibi faktörler açısından etkin olan bu sistem kurutma ihtiyacı duyulan proseslerde başarılı bir şekilde kullanılabilecektir.

$\mathrm{Bu}$ çalışmada, mantar kurutulmasında MC, MR ve DR parametrelerinin tahmini için bir YSA modeli geliştirilmiştir. GDIP kurutucusunda farklı kurutma şartlarında kuruma eğrilerinin deney yapmadan oluşturulabileceği bir model başarılı olarak gerçekleştirilmiştir. Buna göre, yapılan deneylerin farklı sıcaklık ve hava hızı değerlerinde MC, MR ve DR parametreleri başarılı olarak tahmin edilebilir. Bu sayede hem zamandan hem de enerjiden tasarruf yapılarak sistemin hangi sıcaklıklarda nasıl davranacağı kolayca tahmin edilebilecektir. $\mathrm{Bu}$ yöntem, diğer ürünler veya diğer kurutma sıcaklıkları için de tahmin modeli oluşturularak uygulanabilir. $\mathrm{Bu}$ YSA modelinin dilimlenmiş mantarın kuruma süreçlerinin tasarım ve kontrolü için uygulamada yararlı olacağı söylenebilir. Bunun yanında bu çalışmada, mantar kurutma, kurutucular ve kurutma konusunda yapılan modeller ile ilgili olarak araştırmacılara geniş bir literatür sunulmuştur. $\mathrm{Bu}$ modelin veritabanı arttırılarak geliştirilebilir. Yeni bilgilerin ortaya çıkması ve sistemde bazı değişikliklerin olmas1 durumunda hazırlanan bu model yeniden eğitilebilir. 


\begin{tabular}{|c|c|c|c|}
\hline \multicolumn{4}{|c|}{ Kisaltmalar ve Semboller } \\
\hline c & özgül 1sı, kJ (kg K) $)^{-1}$ & $T$ & sicaklık, ${ }^{\circ} \mathrm{C}$ \\
\hline$C O P_{I P}$ & 1S1 pompasinın performans katsayıs1 & $t$ & zaman, s \\
\hline$C O P_{\text {sist }}$ & sistemin performans katsay1s1 & V & hiz, $\mathrm{m} \mathrm{s}^{-1}$ \\
\hline$D R$ & $\begin{array}{l}\text { kurutma hızı, g su (g kuru madde } \\
\mathrm{dk})^{-1}\end{array}$ & $V_{\min }$ & ilgili değişkenin minimum değeri \\
\hline $\mathrm{F}_{\mathrm{k}}$ & kolektör yüzey alan1, $\mathrm{m}^{2}$ & $V_{\max }$ & ilgili değişkenin maksimum değeri \\
\hline$h$ & entalpi, $\mathrm{kJ} \mathrm{kg}^{-1}$ & $V_{n}$ & ilgili değişkenin gerçek değeri \\
\hline$I_{T O P}$ & $\begin{array}{l}\text { kolektör yüzeyine gelen toplam güneş } \\
\text { 1şınımı şiddeti, } \mathrm{W} \mathrm{m}{ }^{-2}\end{array}$ & $\dot{W}_{\text {pomp }}$ & pompanın güç girişi, $\mathrm{kW}$ \\
\hline$\dot{m}$ & kütlesel debi, $\mathrm{kg} \mathrm{s}^{-1}$ & $\dot{W}_{\text {Fan }}$ & fanın güç girişi, $\mathrm{kW}$ \\
\hline$M A P E$ & ortalama mutlak hata yüzdesi & $\eta_{k o l}$ & anlık kolektör verimi \\
\hline$M C$ & nem içeriği, g su (g kuru madde) $)^{-1}$ & & \\
\hline$M C_{K A}$ & $\begin{array}{l}\text { üründeki kuru ağırlığa göre nem } \\
\text { içeriği, g su (g kuru ağırlık)-1 }\end{array}$ & $B N$ & bağıl nem, \% \\
\hline$M C_{Y A}$ & $\begin{array}{l}\text { üründeki yaş ağırlığa göre nem } \\
\text { içeriği, g su (g yaş ağırlık) })^{-1}\end{array}$ & DGGDIP & direkt genleşmeli güneş destekli 1sı pompası \\
\hline$M_{\mathrm{e}}$ & $\begin{array}{l}\text { denge nemi içeriği, g su (g kuru } \\
\text { madde) })^{-1}\end{array}$ & $\operatorname{Exp}$ & deneysel \\
\hline$M_{0}$ & ilk nem içeriği, g su (g kuru madde) $)^{-1}$ & GDIP & güneş destekli 1sı pompası \\
\hline$M_{t}$ & $\begin{array}{l}\text { " } \mathrm{t} \text { ” zamanda nem içeriği, g su (g kuru } \\
\text { madde) })^{-1}\end{array}$ & IP & 1S1 pompas1 \\
\hline$M_{t+d t}$ & $\begin{array}{l}\text { " } \mathrm{t}+\mathrm{dt} \text { " zamanda nem içeriği, } \mathrm{g} \text { su ( } \mathrm{g} \\
\text { kuru madde) })^{-1}\end{array}$ & KA & kuru ağırlık \\
\hline$M R$ & ayrilabilir nem oranı & $\mathrm{KO}$ & kurutma odası \\
\hline RMSE & ortalama hata kareleri karekökü & $L M$ & levenberg-marquardt \\
\hline$R^{2}$ & çoklu belirleme katsayısı & PLC & programlanabilir logic kontrol \\
\hline$Q_{C}$ & kompresör gücü, kW & TKIP & toprak kaynakl1 1s1 pompas1 \\
\hline$\dot{Q}_{E}$ & evaporatör kapasitesi, kW & $Y S A$ & yapay sinir ağ1 \\
\hline$\dot{Q}_{K}$ & kondenser kapasitesi, kW & $Y A$ & yaş ağırlık \\
\hline
\end{tabular}

\section{Kaynaklar}

Aghbashlo M, Mobli H, Rafiee S \& Madadlou A (2012). The use of artificial neural network to predict exergetic performance of spray drying process: A preliminary study. Computers and Electronics in Agriculture 88: $32-43$

Aktaş M, Şevik S, Doğan H \& Öztürk M (2012). Fotovoltaik ve termal güneş enerjili sürekli bir kurutucuda domates kurutulması. Tarlm Bilimleri Dergisi 18: 287-298
Alibaş İ (2012). Asma yaprağının (Vitis vinifera L.) mikrodalga enerjisiyle kurutulması ve bazı kalite parametrelerinin belirlenmesi. Tartm Bilimleri Dergisi 18: $43-53$

Bala B K, Morshed M A \& Rahman M F (2009). Solar drying of mushroom using solar tunnel dryer. International Solar Food Processing Conference, pp. $1-11$

Balbay A, Sahin O, Karabatak M (2011). An investigation of drying process of shelled pistachios in a newly 
designed fixed bed dryer system by using artificial neural network. Drying Technology 29(14): 1685-96

Best R, Cruz J M, Gutierrez J \& Soto W (1996). Experimental results of a solar assisted heat pump rice drying system. Renewable Energy 9: 690-694

Boztok K \& Erkip N (2002). Meşe mantarının (Lentinula edodes) ağaç kütükleri üzerinde yetiştiriciliği. Ege Üniversitesi Ziraat Fakültesi Dergisi 39(1): 149-155

Cakmak G \& Yildiz C (2011). The prediction of seedy grape drying rate using a neural network method. Computers and Electronics in Agriculture 75(1): 132138

Ceylan İ \& Aktaş M (2008a). Isı pompası destekli bir kurutucuda find1k kurutulması. Gazi Üniversitesi Mühendislik-Mimarlık Fakültesi Dergisi 23(1): 215222

Ceylan İ \& Aktaş M. (2008b). Energy analysis of hazelnut drying system-assisted heat pump. International Journal of Energy Research 32: 971-979

Ceylan İ \& Aktas M (2008c). Modeling of a hazelnut dryer assisted heat pump by using artificial neural networks. Applied Energy 85: 841-854

Chen C R, Ramaswamy H S \& Alli I, (2001). Prediction of quality changes during osmo-convective drying of blueberries using neural network models for process optimization. Drying Technology 19(3-4): 507-523

Doymaz İ (2013). Determination of infrared drying characteristics and modelling of drying behaviour of carrot pomace. Tartm Bilimleri Dergisi 19: 44-53

DPT (Devlet Planlama Teşkilatı) 2001. Bitkisel üretim özel ihtisas komisyonu sebzecilik alt komisyon raporu, DPT Sekizinci Beş Yıllık Kalkınma Planı, 2647-ÖİK: 655, Ankara

Erenturk K, Erenturk S, \& Tabil L G (2004). A comparative study for the estimation of dynamical drying behavior of echinacea angustifolia: regression analysis and neural network. Computers and Electronics in Agriculture 45: 71-90

Erenturk S \& Erenturk K (2007). Comparison of genetic algorithm and neural network approaches for the drying process of carrot. Journal of Food Engineering 78(3): 905-912

Esen H, Inallı M, Sengur A \& Esen M (2008). Performance prediction of a ground coupled heat pump system using artificial neural networks. Expert Systems with Applications 35(4): 1940-1948
Esen H \& Inallı M (2009). Modeling of a vertical ground coupled heat pump system by using artificial neural networks. Expert Systems with Applications 36(10): 29-38

EYMSİB (Ege Yaş Meyve Sebze İhracatçıları Birliği) (2010). 2009-2010 dönemi çalışma raporu, EYMSIBB, İzmir, s. 13

Gothandapani L, Parvathi K \& Kennedy Z J (1997). Evaluation of different methods of drying on the quality of oyster mushroom (Pleurotus sp). Drying Technology 15: 1995-2004

Hawlader M N A \& Jahangeer K A (2006). Solar heat pump drying and water heating in the tropics. Solar Energy 80(5): 492-499

Helvacı Ş, Yapar S \& Peker S (1999). Mantar kurutulması için bazı pratik öneriler. Ege Üniversitesi Mühendislik Fakültesi Güncel Konular Serisi, No:1, Kurutma Temel İlkeleri ve Endüstriyel Uygulamaları, (Eds. S. Peker, S. Yapar), 47-52, İzmir

Hernandez-Perez J A, Garcia-Alvarado M A, Trystram G \& Heyd B (2004). Neural networks for heat and mass transfer prediction during drying of cassava and mango. Innovative Food Science and Emerging Technologies 5: 57-64

Hussain M A, Rahman M S, Ng C W (2002). Prediction of pores formation (porosity) in foods during drying: generic modes by the use of hybrid neural network. Journal of Food Engineering 51: 239-248

Jambrak A R, Mason T J, Paniwnyk L \& Lelas V (2007). Accelerated drying of button mushrooms, brussels sprouts and cauliflower by applying power ultrasound and its rehydration properties. Journal of Food Engineering 81: 88-97

Jang J-S R, Sun C T \& Mizutani E (1997). Neuro-fuzzy and soft computing: A computational approach to learning and machine intelligence. Prentice-Hall International 42(10): 1482-1484

Kahyaoğlu A G (2008). Kurutulmuş sebzeler. TC. Başbakanlık Diş Ticaret Müsteşarlığı İhracatı Geliştirme Etüd Merkezi, SITC No 056.1, Armonize No: 0712

Karimi F, Rafiee S, Taheri-Garavand A \& Karimi M (2012). Optimization of an air drying process for Artemisia absinthium leaves using response surface and artificial neural network models. Journal of Taiwan Institute of Chemical Engineering 43: 29-39

Khoshhal A, Alizadeh Dakhel A, Etemad A \& Zereshki S (2010). Artificial neural network of apple drying 
process. Journal Food Process Engineering 33 (1): 298-313

Kulshreshtha M, Singh A, Deepti \& Vipul (2009). Effect of drying conditions on mushroom quality. School of Engineering, Taylor's University College, Journal of Engineering Science and Technology 4(1): 90-98

Li H, Dai Y, Dai J, Wang X \& Wei L (2010). A solar assisted heat pump drying system for grain in-store drying. Frontiers of Energy and Power Engineering in China 4(3): 386-391

Lidhoo C K \& Agrawal Y C (2008). Optimizing temperature in mushroom drying. Journal of Food Processing \& Preservation 32(6): 881-897

Menlik T, Kirmacı V \& Usta H (2009). Modeling of freeze drying behaviors of strawberries by using artificial neural network. Journal of Thermal Science and Technology 29(2): 11-21

Menlik T, Özdemir M B \& Kirmacı V (2010). Determination of freeze-drying behaviors of apples by artificial neural network. Expert Systems with Applications 37(12): 7669-77

Midilli A, Olgun H \& Ayhan T (1999). Experimental studies of mushroom and polen drying. International Journal of Energy Research 23: 1143-1152

Mohanraj M, Jayaraj S \& Muraleedharan C (2009). Performance prediction of a direct expansion solar assisted heat pump using artificial neural networks. Applied Energy 86: 1442-9

Movagharnejad K \& Nikzad M (2007). Modeling of tomato drying using artificial neural network. Computers and Electronics in Agriculture 59: 78-85

Nazghelichi T, Kianmehr M H \& Aghbashlo M (2011). Prediction of carrot cubes drying kinetics during fluidized bed drying by artificial neural network. Journal of Food Science and Technology 48(5): 54250

Nehru C, Kumar V, Maheswari C \& Gothandapani L (1995). Solar drying characteristics of oyster mushroom. Mushroom Research 4(1): 27-30

Omid M, Baharlooei A \& Ahmadi H (2009). Modeling drying kinetics of pistachio nuts with multilayer feedforward neural network. Drying Technology 27(10): 1069-77

Pal U S \& Chakraverty A (1997). Thin-layer convectiondrying of mushrooms. Energy Conversion and Management 38(2): 107-113
Palancar M C, Aragon J M \& Castellanos J A (2001). Neural network model for fluidized bed dryers. Drying Technology 19(6): 1023-44

Poonnoy P, Tansakul A \& Chinnan M (2007). Artificial neural network modeling for temperature and moisture content prediction in tomato slices undergoing microwave-vacuum drying. Journal of Food Science 72(1): 42-7

Satish S \& Pydi Setty Y (2005). Modeling of a continuous fluidized bed dryer using artificial neural networks. International Communications in Heat and Mass Transfer 32: 539-47

Sözen A, Arcaklığlu E, Menlik T \& Özalp M (2009). Determination of thermodynamic properties of an alternative refrigerant (R407c) using artificial neural network. Expert Systems with Applications 36: 434656

Sporn P \& Ambrose E R (1955). The heat pump and solar energy. In: Proceedings of the World Symposium on Applied Solar Energy, November 1-5, Phoenix, Arizona, USA

Şevik S (2011). Isı Pompası ve Güneş Kolektörünün Birlikte Kullanıldığı, Isıtma ve Kurutma Amaçlı Sıcak Hava Üretim Sisteminin Tasarımı, İmalatı ve Deneysel İncelenmesi. Doktora Tezi, Gazi Üniversitesi Fen Bilimleri Enstitüsü (Yayımlanmamış), Ankara

Şevik S, Aktaş M, Doğan H \& Koçak S (2013). Mushroom drying with solar assisted heat pump system. Energy Conversion and Management 72: 171-178

Şevik S (2013). Design, experimental investigation and analysis of a solar drying system. Energy Conversion and Management 68: 227-234

Toğrul H, Toğrul İ \& İspir A (2005). Mantarların ince tabaka kuruma karakteristiklerinin incelenmesi. III. Tarımsal Ürünleri Kurutma Çalıştayı, Antalya

Wu H \& Avramidis S (2006). Prediction of timber kiln drying rates by neural networks. Drying Technology 24(12): 1541-5

Xanthopoulos G, Lambrinos G \& Manolopoulou H (2007). Evaluation of thin-layer models for mushroom (agaricus bisporus) drying. Drying Technology 25: 1471-81

Zhang Q H, Yang S X, Mittal G S \& Shujuan Y J (2002). Prediction of performance indices and optimal parameters of rough rice drying using neural networks. Biosystems Engineering 83(3): 281-290. 